23 Bourke DL, Warley A. The steady state and rebreathing methods compared during morphine administration in methods compared during morphine

24 Santiago TV, Johnson J, Riley DJ, Edelman NH. Effects of morphine on ventilatory response to exercise. $\mathcal{F} A p p$ Physiol 1979;47:112-8.

25 Aitken RCB. Measurement of feelings using visual analogue scales. Proc $R$ Soc Med 1969;62:989-93.

26 Stark RD, Gambles SA, Chatterjee SS. An exercise test to assess clinical dyspnoea: estimation of reproducibility and sensitivity. $B r \mathcal{F}$ Dis Chest 1982;76:269-78.

27 Wilson RC, Jones PW. A comparison of the visual analogue scale and modified Borg scale for the measurement of dyspnoea during exercise. Clin Sci 1989;76:277-82.

28 Muza SR, Silverman MT, Gilmore GC, Hellerstein HK, Kelsen SG. Comparison of scales used to quantitate the sense of effort to breathe in patients with chronic obstructive pulmonary disease. Am Rev Respir Dis 1990;141: 909-13.
29 Masters NJ, Bennett MA, Wedley JR. Nebulised morphine: a new delivery method for pain relief. Practitioner 1985; 229:649-53.

30 Chrubasik J, Wüst H, Friedrich G, Geller E. Absorption and bioavailability of nebulised morphine. Br $\mathcal{F}$ Anaesth 1988;61:228-30.

31 Davis C. Symptomatic management of breathlessness. Some of the more unusual pharmacological options. In: Research aspects of the palliation of breathlessness. Workshop, Royal Marsden Hospital and Institute of Cancer Research, October 1993.

32 Kirsch JL, Munro JR, Stansbury DW, Fischer CE, Manfore $R$, Light RW. Effect of naloxone on maximal exercise performance and control of ventilation in COPD. Chest 1989;96:761-6.

33 Winning AJ, Hamilton RD, Guz A. Ventilation and breathlessness on maximal exercise in patients with interstitia lung disease after local anaesthetic aerosol inhalation. Clin Sci 1988;74:275-81.

\title{
"Non-tuberculous mycobacteria"
}

I have been concerned for many years with some logical difficulties in discourse about mycobacterial diseases ${ }^{1}$ and have concluded that some, at least, of this continued confusion arises from the adoption in the current nomenclature of mycobacteria of the specific name tuberculosis for the species most commonly associated with tuberculosis in the human subject. In colloquial discourse this organism has always been called the human tubercle bacillus with clarity and propriety, and it is regrettable that in the formal terminology of the mycobacteria this was not translated into Latin as Mycobacterium hominis. The increasing use of such absurd terms as "non-tuberculous mycobacteria" impels me to return to this theme.

We must surely accept that "tuberculosis" currently refers to a disease, in man or other animals, characterised by granulomatous changes caused by mycobacteria, and must not confuse this disease with its own cause. A diagnosis of tuberculosis places the patient in a category with defining characteristics in two fields - morbid anatomy and aetiology. A complete diagnostic statement would include identification of the causal mycobacterium. When a diagnosis of tuberculosis (unspecified) is made in man, it is an acceptable convention that the causal organism is thought, or has been shown, to be the human tubercle bacillus. In the days when disease caused by Mycobacterium bovis was important in man we referred to it as bovine tuberculosis, implying with perfect clarity disease caused by the species of mycobacterium most commonly causing disease in cattle. The adoption of the name hominis for the species most prevalent in the human race would have been logical and convenient, and would not have implied that only the disease caused by this species is properly called tuberculosis - leaving in limbo granulomatous dis- eases caused in man by other species of mycobacteria - and raising interesting logical questions about the nomenclature of granulomatous diseases caused by various species of mycobacteria in other animals.

Since tuberculosis is a compound diagnostic category with morbid anatomical and aetiological defining characteristics, the argument that epidemiological considerations justified the specific name tuberculosis for the mycobacterium most important in man was always weak since the aetiological term in the diagnostic label is evidently the one most relevant to epidemiology. Indeed, it was always recognised that the epidemiology of the disease caused in man by $M$ bovis and uncontroversially called tuberculosis was epidemiologically distinct. I see no reason why it should not be proper to speak of tuberculosis caused by any species of mycobacterium. We may properly refer to nontuberculous mycobacterial disease if we encounter one of the rare cases of acute mycobacteriosis causing only necrotic and nongranulomatous changes; but I see no logical justification for the ghastly term "non-tuberculous mycobacteria" which seems to imply mycobacteria that do not cause tuberculoid granulomatous changes. Presumably the excuse for this clumsy usage is that it is to be understood as referring to mycobacteria other than $M$ tuberculosis. We should always be prepared to use a few extra words to express our meaning clearly and logically. If the human tubercle bacillus had been called $M$ hominis we could refer to what I think (but am sometimes left uncertain) is intended by "non-tuberculous mycobacteria" as "mycobacteria other than $M$ hominis" without unwanted implications.

J G SCADDING

1 Scadding JG. Nomenclature of mycobacterial disease. $A m$ Rev Respir Dis 1987;136:1308-9. 